\title{
Laparoscopic Posterolateral Rectopexy for the Treatment of Patients With a Full Thickness Rectal Prolapse: Experience With 63 Patients and Short-term Outcomes
}

\author{
Keehoon Hyun, Shi-Jun Yang, Ki-Yun Lim, Jong-Kyun Lee, Seo-Gue Yoon \\ Department of Surgery, Seoul Song Do Hospital, Seoul, Korea
}

Purpose: Although numerous procedures have been proposed for the treatment of patients with a rectal prolapse, the most effective operation has not yet been established. Minimal rectal mobilization can prevent constipation; however, it is associated with increased recurrence rates. We describe our novel method for a laparoscopic posterolateral rectopexy, which includes rectal mobilization with a posterior-right unilateral dissection, suture fixation to the sacral promontory with a polypropylene mesh (Optilene), and a mesorectal fascia propria that is as wide as possible. The present report describes our novel method and assesses the short-term outcomes of patients.

Methods: Between June 2014 and June 2017, 63 patients (28 males and 35 females) with a full-thickness rectal prolapse underwent a laparoscopic posterolateral (LPL) rectopexy. We retrospectively analyzed the clinical characteristics and postoperative complications in those patients. The outcome of surgery was determined by evaluating the answers on fecal incontinence questionnaires, the results of anal manometry preoperatively and 3 months postoperatively, the patients' satisfaction scores (0-10), and the occurrence of constipation.

Results: No recurrence was reported during follow-up (3.26 months), and 3 patients reported postoperative complications (wound infection, postoperative sepsis, which was successfully treated with conservative management, and retrograde ejaculation). Compared to the preoperative baseline, fecal incontinence at three months postoperatively showed an overall improvement. The mean patient satisfaction score was $9.55 \pm 0.10$, and 8 patients complained of persistent constipation. Conclusion: LPL rectopexy is a safe, effective method showing good functional outcomes by providing firm, solid fixation for patients with a full-thickness rectal prolapse.

Keywords: Rectal prolapse; Posterior mesh rectopexy; Constipation

\section{INTRODUCTION}

Rectal prolapse is the circumferential protrusion of the rectal wall through the anal canal. This condition is an embarrassing and socially debilitating disability that causes pain, fecal incontinence,

Received: November 18, 2017 - Accepted: January 31, 2018

Correspondence to: Seo-Gue Yoon, M.D.

Department of Surgery, Seoul Song Do Hospital, 78 Dasan-ro, Jung-gu,

Seoul 04597, Korea

Tel: +82-2-2250-7368, Fax: +82-2-2233-8528

E-mail:seogue@naver.com

ORCID code: https://orcid.org/0000-0001-7770-758X

(C) 2018 The Korean Society of Coloproctology

This is an open-access article distributed under the terms of the Creative Commons Attribution NonCommercial License (http://creativecommons.org/licenses/by-nc/4.0) which permits unrestricted noncommercial use, distribution, and reproduction in any medium, provided the original work is properly cited. difficult evacuation, mucus discharge, and bleeding [1]. Although over 100 different operations have been described for the correction of rectal prolapse, including perineal and abdominal approaches, a consensus regarding an optimal treatment strategy is lacking [2]. Laparoscopic ventral rectopexy (LVR) is an autonomic nerve-sparing technique of anterior rectal suspension involving minimal rectal mobilization [3]. LVR is currently adopted by many pelvic floor surgeons because of the good functional results and the wide range of indications for its use, such as enteroceles and rectoceles [4]. LVR has been emerging as the procedure of choice for the management of patients presenting with rectal prolapse, particularly in Europe [5]. However, the subject is still a matter for debate.

A minimal rectal mobilization procedure can prevent postoperative constipation; however, such a procedure is associated with 
an increased recurrence rate [6]. Fu and Stevenson [7] reported that a sufficiently wide mesh and suture in the midrectum should be added because a narrow mesh and inadequate apposition between the mesh and the rectum can contribute to technical failure of the LVR. However, use of a wide mesh in the rectovaginal septum could increase the potential risk of complications. Use of a synthetic mesh can cause erosion, rectal strictures, rectovaginal fistulae, and chronic pelvic pain [8]. Biologic grafts have been used to avoid these complications; however, their use is associated with higher recurrence rates.

The fascia propria of the rectum is a collagen-rich layer, which is significantly thicker in the posterior than in the anterior portion [9] and can be easily identified during posterior dissection along the retrorectal avascular space. Therefore, suturing the posterior segment of the fascia propria of the rectum is expected to be a simpler procedure and to provide a stronger fixation than that obtained by suturing the anterior wall. Additionally, it does not leave a mesh in the rectovaginal septum, which would, therefore, prevent the potential risks.

The cause of postoperative constipation after a rectopexy remains unclear. However, autonomic nerve injury due to division of the lateral ligaments of the rectum is accepted as the one of the causes of postoperative constipation [10]. For purposes of rectal mobilization, a conventional posterior mesh rectopexy and a suture rectopexy are performed using a technique of circular dissection and division of both lateral ligaments. Our novel method of laparoscopic posterolateral (LPL) rectopexy involves dissection in the posterior and only the right lateral sidewall of the rectum to obtain rectal mobilization. The left side is not manipulated, thereby ensuring nerve preservation. This report describes this unique technique and details regarding patients' outcomes following the procedure.

\section{METHODS}

This study was approved by the Institutional Review Boards of the participating institutions. Between June 2014 and June 2017, 63 patients diagnosed with a full-thickness rectal prolapse underwent a LPL rectopexy at Seoul Songdo Hospital, Seoul, Korea. All procedures were performed by a single experienced surgeon. Patients were diagnosed based on clinical examination findings and were confirmed radiologically. Demographic data, medical history, and surgical and follow-up details of the patients were recorded. Fecal incontinence was assessed using questionnaires such as the Cleveland Clinic Incontinence Score (CCIS, Wexner score), the fecal incontinence severity index (FISI), and the fecal incontinence quality of life (FIQOL) scale [11, 12]. All patients underwent preoperative colonoscopy to exclude intraluminal pathology. Magnetic resonance imaging was performed to evaluate sphincter integrity. All patients underwent anal manometry and pudendal nerve terminal motor latency (PNTML) testing for evaluation of anorectal physiology.
Patients were first evaluated 2 weeks postoperatively and were then followed up for evaluation of postoperative complications and recurrence. Patients were re-evaluated 3-4 months postoperatively, and patients' satisfaction scores $(0-10)$ and the occurrence of constipation, if any, were recorded. A physical examination was performed to evaluate postoperative complications and/or recurrence. Defecation proctography was performed, and fecal incontinence questionnaires using CCIS, FISI, and the FIQOL Scale were completed. Additionally, we performed anal manometry and PNTML testing.

All patients received a conventional preoperative bowel preparation before surgery, and a single dose of an intravenous broadspectrum antibiotic was administered. A urinary catheter was placed after induction of general anesthesia. The procedures were performed with the patient placed in the lithotomy position with Trendelenburg tilting to achieve small bowel retraction. The operation was performed using 5 trocars: a $12-\mathrm{mm}$ balloon trocar at the umbilicus, a 5-mm trocar in the right upper quadrant, an 11$\mathrm{mm}$ trocar in the right iliac fossa, a 5-mm trocar in the left upper quadrant, and a 5-mm trocar inserted in the left iliac fossa. The surgeon stood to the lower right side of the patient, with the scopist on the upper right side of the patient, and the assistant on the left side.

The sigmoid colon was retracted from the pelvic cavity and sutured to the left abdominal wall by using 2-0 nylon. In female patients, the uterus was fixed to the anterior abdominal wall in a similar fashion. An inverted J-shaped peritoneal opening was created along the posterior-right lateral-anterior side of the rectum from the sacral promontory to the Douglas pouch. Posterior dissection was performed for rectal mobilization along the plane of the fascia propria of the rectum through the retrorectal avascular space from the sacral promontory to the coccyx. To avoid nerve injury, we minimized the lateral dissection of the right side by preserving the lateral ligaments containing rectal branches from the pelvic plexus and then pulling the rectum in a cranial direction to confirm reduction of the prolapse. If an adequate anatomical correction of the prolapse was not achieved, the lateral ligament was divided to enable better mobilization. The anterior dissection was performed at the upper third portion of rectum.

Polypropylene mesh (Optilene, B.Braun Surgical, Rubi, Spain, incised with width $1.5 \mathrm{~cm}$ and length $12 \mathrm{~cm}$ ) was prepared and introduced into the abdominal cavity through an $11-\mathrm{mm}$ trocar. The rectum was lifted by the assistant, and the mesh was fixed to the periosteum of the sacral promontory by using an absorbable monofilament (Monosyn, B.Braun Surgical) suture. The posterior rectal and right lateral mesorectal fascia propria were sutured as wide as possible with the mesh (Fig. 1A). The fixation was reinforced by suturing twice using nonabsorbable polypropylene (Prolene, Ethicon, Puerto Rico, TX, USA).

After posterior fixation, we performed lateral fixation. During peritoneal closure, we suspected that suturing only the peritoneum would not provide a robust enough repair to support the 

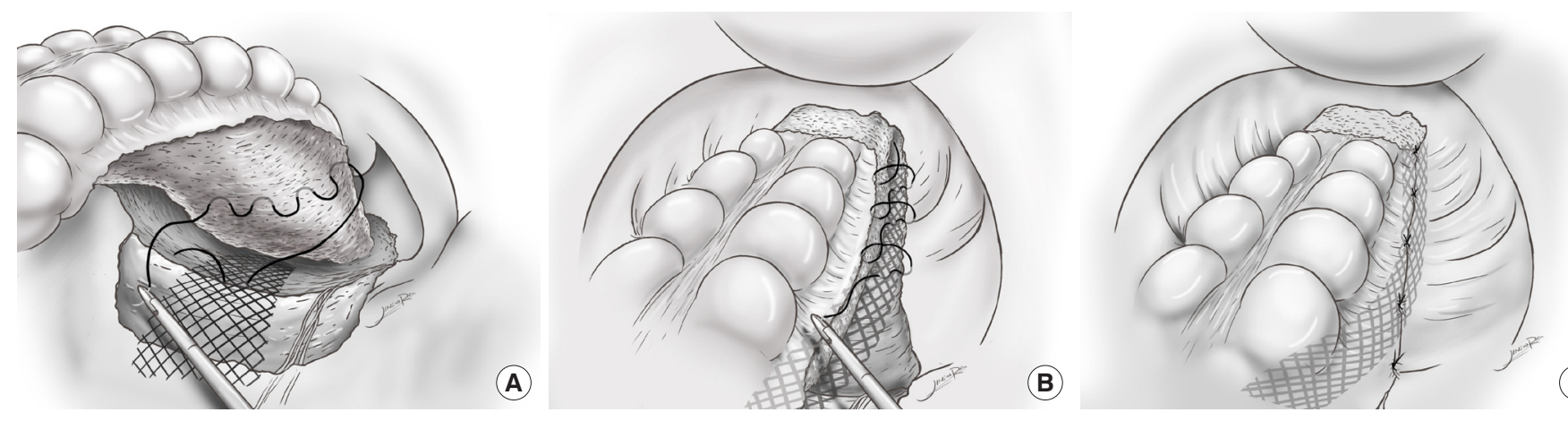

(C)

Fig. 1. (A) Posterior fixation. The mesh is fixed to the periosteum of the sacral promontory, and the rectal fascia propria is sutured as wide as possible. (B) Lateral fixation. The peritoneum and the right mesorectal fascia propria are sutured by using continuous interlocking sutures with mesh. (C) The anterior peritoneum remains open for use as a drainage window.

Table 1. Patients' demographics and preoperative characteristics (n $=63)$

\begin{tabular}{lc}
\hline Characteristic & Value \\
\hline Age $(\mathrm{yr})$ & $60.87 \pm 2.18$ \\
Sex, male : female & $28: 35$ \\
Body mass index $\left(\mathrm{kg} / \mathrm{m}^{2}\right)$ & $23.72 \pm 0.44$ \\
Chief complaint & \\
$\quad$ Fecal incontinence & 24 \\
Difficult evacuation & 7 \\
Previous abdominal approach & 4 \\
Previous perineal approach & 3 \\
\hline
\end{tabular}

Values are presented as mean \pm standard deviation or number.

rectum. Therefore, we placed a mesh between the lateral peritoneum and right lateral mesorectal fascia propria. And we performed a continuous absorbable suture to support additional traction of the mid rectum (Fig. 1B). The peritoneum on the anterior side was left open as a drainage window for blood and discharge (Fig. 1C).

Quantitative data were expressed as medians and ranges. Statistical analyses were performed using the paired t-test for paired data. A P-value $<0.05$ was considered statistically significant.

\section{RESULTS}

Between June 2014 and June 2017, 63 patients underwent the LPL procedure. The mean age of the patients was 60.87 years, the youngest being 20 and the oldest 90 (Table 1). Male patients were 28 (44.44\%), and female patients were 35 (55.56\%). The most common presenting symptom at the time of the patient's first visit was fecal incontinence $(\mathrm{n}=24)$, followed by difficult evacuation $(\mathrm{n}=7)$, anal bleeding $(\mathrm{n}=7)$, and perianal pain $(\mathrm{n}=7)$. We noted that 7 patients $(11 \%)$ had previously undergone operations for repair of a prolapse; 3 patients underwent perineal procedures and 4 underwent an abdominal rectopexy. Of note, 16 patients re-
Table 2. Preoperative and postoperative incontinence functional data and anal sphincter function

\begin{tabular}{lccr}
\hline Variable & Preoperative & Postoperative & P-value \\
\hline Wexner score & $9.21 \pm 6.52$ & $4.36 \pm 6.16$ & $<0.001$ \\
FISI score & $24.04 \pm 15.12$ & $15.92 \pm 3.59$ & 0.021 \\
FIQOL score & $13.56 \pm 4.14$ & $19.19 \pm 11.99$ & 0.027 \\
$\begin{array}{l}\text { Maximum resting pressure } \\
\text { (mmHg) }\end{array}$ & $37.30 \pm 16.14$ & $38.61 \pm 17.29$ & 0.458 \\
$\begin{array}{l}\text { Maximum squeezing pressure } \\
(\mathrm{mmHg})\end{array}$ & $87.61 \pm 56.30$ & $89.37 \pm 59.04$ & 0.671 \\
\hline
\end{tabular}

FISI, fecal incontinence severity index; FIQOL, fecal incontinence quality of life.

ported a history of other abdominal operations.

No intraoperative complications and postoperative mortality were reported. Postoperative complications were observed in 3 patients: 1 patient with a wound infection, 1 with postoperative pelvic sepsis, which was successfully treated with conservative management, and 1 with retrograde ejaculation. The median follow-up was 3.26 months, and no recurrence was observed in any patient during that period. The mean patient satisfaction score was $9.55 \pm 0.10$. Patients reported a statistically significant improvement in fecal incontinence and quality of life at the 3-month follow-up compared to the preoperative baseline (Table 2, Fig. 2). No statistically significant changes in the results of anal manometry were noted. Of the 7 patients who complained of preoperative constipation, 5 showed an alleviation of their symptoms. Newonset constipation was observed in 6 of 53 patients (10.7\%) who had been asymptomatic preoperatively.

\section{DISCUSSION}

We aimed to describe the stability and efficacy of a LPL rectopexy procedure. No recurrence was noted in any patient during the follow-up period, and the postoperative complication rate was $4.7 \%$ ( 3 of 63). This result is relatively low compared to the postopera- 
Wexner score

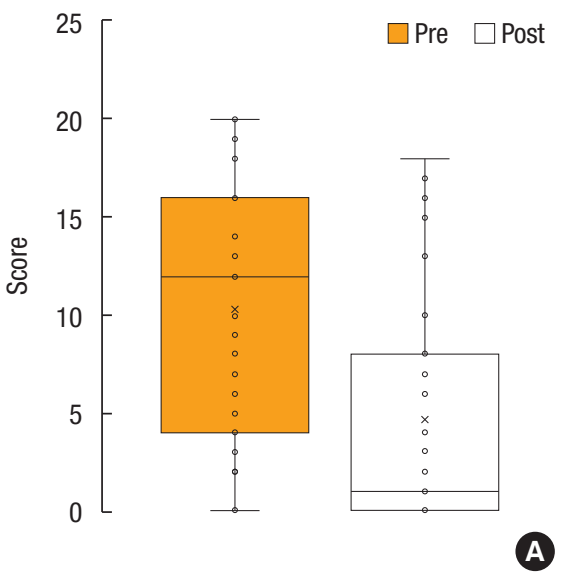

FIQOL score

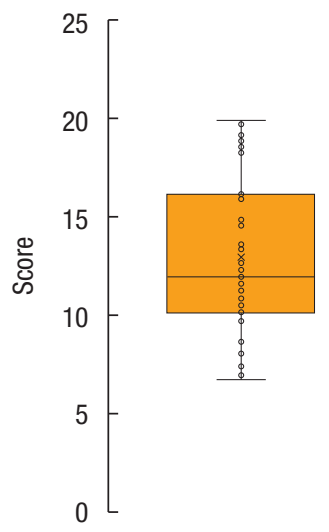

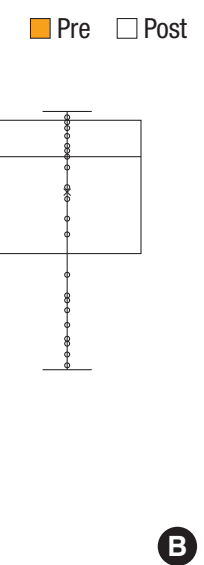

FISI score

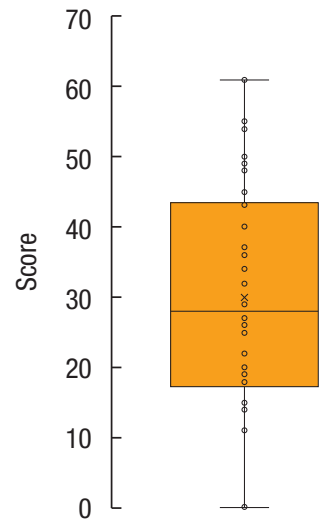

B

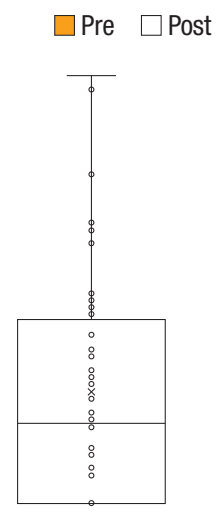

C

Fig. 2. Box plots of the Wexner score (A), fecal incontinence quality of life (FIQOL) score (B), and fecal incontinence severity index (FISI) score $(\mathrm{C})$.

tive complication rate of $1.4 \%-47 \%$ following a rectopexy [13]. A successful and effective rectopexy requires a solid, firm fixation to avoid technical failure and recurrence. Two strategies are used to achieve this goal. The first is the suturing of the fascia propria of the rectum. A standardized suture position or layer on the rectum has not been described for a rectopexy. The few published reports that are available do not clearly describe the suture location, which is often vaguely referred to as the anterior rectal wall or the seromuscular wall or, as is noted in some reports, it is not mentioned at all $[3,14-16]$. This ambiguity may lead to technical failure. Thus, a precise description of the suture layers is required. We believe the fascia propria of the rectum to be the most appropriate layer for the placement of sutures. The fascia propria is composed of collagen-rich tissue surrounding the rectum and the mesorectum. Suturing the posterior fascia propria in a rectopexy has several advantages. The posterior fascia propria is thicker than the anterior layer, which reduces the risk of puncturing the rectal lumen during suturing. In addition, the posterior fascia propria is easily identifiable during retrorectal avascular space dissection [9]. The second strategy for ensuring firm fixation is to suture the periosteum of the sacral promontory. We prefer hand suturing over the use of tacks when fixing the mesh to the sacrum because the surgeon's hands can better sense any mobility and can confirm whether the periosteum has been appropriately sutured.

Based on 11 studies [17-27], D'Hoore et al. and the Cochrane review have demonstrated a high incidence of postoperative constipation after a posterior mesh rectopexy and explained the validity of autonomic nerve-conservation surgery $[3,10]$. However, all those studies except one described open abdominal procedures [27]. Because the use of laparoscopy can introduce a bias in the study results, further studies should evaluate the results of laparoscopic procedures. Although the evidence is limited due to the small numbers of patients studied, a randomized clinical trial has shown that the incidence of severe postoperative constipation is less in a laparoscopic posterior mesh rectopexy group than in an open posterior rectopexy group [28]. The mechanism of constipation associated with a rectopexy remains unclear. Autonomic nerve injury cannot explain the lower incidence of constipation observed after a resection rectopexy [29]. Even if the autonomic nerve injury mechanism is correct, an LPL rectopexy is a unilateral dissection, and all the left-sided tissues ranging from the peritoneum to the lateral ligament are preserved. New-onset constipation after an LPL rectopexy was observed in 6 of 56 patients (10.7\%) who had been asymptomatic preoperatively. This is an acceptable result compared to the $14.4 \%$ weighted mean rate of LVR [13].

Many surgeons are concerned about mesh-related complications. Rectal strictures, mesh erosion, and genitourinary injuries have been reported due to the presence of a mesh in the rectovaginal septum [8]. In men, these may occur from minor complications ranging from urinary retention to sexual dysfunction [30]. Therefore, a LPL rectopexy would be a good alternative for young male patients.

The present study had several limitations. The 3- to 4-month follow-up was too short to evaluate and confirm the low rate of recurrence. A long-term follow-up study to build on these data is planned. According to recent research, the largest number of recurrences occurs within the first 12 months after surgery [7]. In consideration of this result, we expect our study may help demonstrate that the LPL rectopexy is a procedure with a low recurrence rate. Although mesh-related complications in posterior wall procedures are rare, the long-term effects of permanent mesh placement have not been recorded. Moreover, the evaluation of constipation was performed by using only simple yes or no questions. A detailed study in which the answers on the questionnaires about constipation are scored will be necessary. 
In summary, the LPL rectopexy is a novel procedure that provides firm, solid fixation for patients presenting with a full-thickness rectal prolapse. The advantages of this technique are its low complication rate, alleviated symptoms of incontinence, and an acceptable prevalence of new-onset postoperative constipation. Further studies with long-term follow-up are warranted for a better determination of the recurrence rates noted with this technique.

\section{CONFLICT OF INTEREST}

No potential conflict of interest relevant to this article was reported.

\section{REFERENCES}

1. Bordeianou L, Hicks CW, Kaiser AM, Alavi K, Sudan R, Wise PE. Rectal prolapse: an overview of clinical features, diagnosis, and patient-specific management strategies. J Gastrointest Surg 2014; 18:1059-69.

2. Yoon SG. Rectal prolapse: review according to the personal experience. J Korean Soc Coloproctol 2011;27:107-13.

3. D'Hoore A, Cadoni R, Penninckx F. Long-term outcome of laparoscopic ventral rectopexy for total rectal prolapse. Br J Surg 2004; 91:1500-5.

4. Formijne Jonkers HA, Poierrié N, Draaisma WA, Broeders IA, Consten EC. Laparoscopic ventral rectopexy for rectal prolapse and symptomatic rectocele: an analysis of 245 consecutive patients. Colorectal Dis 2013;15:695-9.

5. Mercer-Jones MA, D'Hoore A, Dixon AR, Lehur P, Lindsey I, Mellgren A, et al. Consensus on ventral rectopexy: report of a panel of experts. Colorectal Dis 2014;16:82-8.

6. Bishawi M, Foppa C, Tou S, Bergamaschi R; Rectal Prolapse Recurrence Study Group. Recurrence of rectal prolapse following rectopexy: a pooled analysis of 532 patients. Colorectal Dis 2016; 18:779-84.

7. Fu CW, Stevenson AR. Risk factors for recurrence after laparoscopic ventral rectopexy. Dis Colon Rectum 2017;60:178-86.

8. Badrek-Al Amoudi AH, Greenslade GL, Dixon AR. How to deal with complications after laparoscopic ventral mesh rectopexy: lessons learnt from a tertiary referral centre. Colorectal Dis 2013; 15:707-12.

9. Bisset IP, Chau KY, Hill GL. Extrafascial excision of the rectum: surgical anatomy of the fascia propria. Dis Colon Rectum 2000; 43:903-10.

10. Tou S, Brown SR, Nelson RL. Surgery for complete (full-thickness) rectal prolapse in adults. Cochrane Database Syst Rev 2015;(11): CD001758.

11. Rockwood TH, Church JM, Fleshman JW, Kane RL, Mavrantonis C, Thorson AG, et al. Patient and surgeon ranking of the severity of symptoms associated with fecal incontinence: the fecal incontinence severity index. Dis Colon Rectum 1999;42:1525-32.
12. Rockwood TH, Church JM, Fleshman JW, Kane RL, Mavrantonis C, Thorson AG, et al. Fecal incontinence quality of life scale: quality of life instrument for patients with fecal incontinence. Dis Colon Rectum 2000;43:9-16; discussion 16-7.

13. Samaranayake CB, Luo C, Plank AW, Merrie AE, Plank LD, Bissett IP. Systematic review on ventral rectopexy for rectal prolapse and intussusception. Colorectal Dis 2010;12:504-12.

14. Powar MP, Ogilvie JW Jr, Stevenson AR. Day-case laparoscopic ventral rectopexy: an achievable reality. Colorectal Dis 2013;15: 700-6.

15. van Iersel JJ, Formijne Jonkers HA, Paulides TJC, Verheijen PM, Draaisma WA, Consten ECJ, et al. Robot-assisted ventral mesh rectopexy for rectal prolapse: a 5-year experience at a tertiary referral center. Dis Colon Rectum 2017;60:1215-23.

16. Gosselink MP, Adusumilli S, Gorissen KJ, Fourie S, Tuynman JB, Jones OM, et al. Laparoscopic ventral rectopexy for fecal incontinence associated with high-grade internal rectal prolapse. Dis Colon Rectum 2013;56:1409-14.

17. Holmström B, Brodén G, Dolk A. Results of the Ripstein operation in the treatment of rectal prolapse and internal rectal procidentia. Dis Colon Rectum 1986;29:845-8.

18. Mann CV, Hoffman C. Complete rectal prolapse: the anatomical and functional results of treatment by an extended abdominal rectopexy. Br J Surg 1988;75:34-7.

19. Yoshioka K, Heyen F, Keighley MR. Functional results after posterior abdominal rectopexy for rectal prolapse. Dis Colon Rectum 1989;32:835-8.

20. Allen-Mersh TG, Turner MJ, Mann CV. Effect of abdominal Ivalon rectopexy on bowel habit and rectal wall. Dis Colon Rectum 1990;33:550-3.

21. Sayfan J, Pinho M, Alexander-Williams J, Keighley MR. Sutured posterior abdominal rectopexy with sigmoidectomy compared with Marlex rectopexy for rectal prolapse. Br J Surg 1990;77:1435.

22. Delemarre JB, Gooszen HG, Kruyt RH, Soebhag R, Geesteranus AM. The effect of posterior rectopexy on fecal continence. A prospective study. Dis Colon Rectum 1991;34:311-6.

23. Hiltunen KM, Matikainen M. Clinical results of abdominal rectopexy for rectal prolapse. Ann Chir Gynaecol 1991;80:263-6.

24. Luukkonen P, Mikkonen U, Järvinen H. Abdominal rectopexy with sigmoidectomy vs. rectopexy alone for rectal prolapse: a prospective, randomized study. Int J Colorectal Dis 1992;7:21922.

25. Novell JR, Osborne MJ, Winslet MC, Lewis AA. Prospective randomized trial of Ivalon sponge versus sutured rectopexy for fullthickness rectal prolapse. Br J Surg 1994;81:904-6.

26. Aitola PT, Hiltunen KM, Matikainen MJ. Functional results of operative treatment of rectal prolapse over an 11-year period: emphasis on transabdominal approach. Dis Colon Rectum 1999; 42:655-60.

27. Benoist S, Taffinder N, Gould S, Chang A, Darzi A. Functional results two years after laparoscopic rectopexy. Am J Surg 2001; 


\section{Coloproctology Keehoon Hyun, et al.}

\section{2:168-73.}

28. Boccasanta P, Rosati R, Venturi M, Montorsi M, Cioffi U, De Simone $\mathrm{M}$, et al. Comparison of laparoscopic rectopexy with open technique in the treatment of complete rectal prolapse: clinical and functional results. Surg Laparosc Endosc 1998;8:460-5.

29. Senapati A, Gray RG, Middleton LJ, Harding J, Hills RK, Armit- age NC, et al. PROSPER: a randomised comparison of surgical treatments for rectal prolapse. Colorectal Dis 2013;15:858-68.

30. Siddika A, Saha S, Siddiqi S. Evolution of male rectal prolapse surgery and initial experience of robotic rectopexy in men. J Robot Surg 2017;11:311-6. 